http://jmscr.igmpublication.org/home/ ISSN (e)-2347-176x ISSN (p) 2455-0450

crossref DOI: https://dx.doi.org/10.18535/jmscr/v7i12.71

Journal Of Medical Science And Clinical Research

\title{
Original Research Article \\ Study of Ocular Complications of Diabetes Mellitus in Patients Attending in Tertiary Care Hospital at S.K.M.C.H., Muzaffarpur, Bihar
}

\author{
Authors \\ Dr Rajiv Kumar Singh ${ }^{1}$, Dr. Ramakant Thakur ${ }^{2 *}$ \\ ${ }^{1}$ Associate Professor and H.O.D, Department of Ophthalmology, S. K. Medical College and Hospital, \\ Muzaffarpur \\ ${ }^{2}$ Assistant Professor, Department of Ophthalmology, S. K. Medical College and Hospital, Muzaffarpur \\ *Corresponding Author \\ Dr Ramakant Thakur
}

Assistant Professor, Department of Ophthalmology, S. K. Medical College and Hospital, Muzaffarpur

\begin{abstract}
Objectives: There is an increasing prevalence and incidence of diabetes mellitus with advancing age, adult diabetics are also at risk of vision threatening retinopathies. A fourth of the world's blind population is resides in India. Ocular complications due to diabetes mellitus manifests in various ways, but manifestations of diabetes other than diabetic retinopathy are easily overlooked. The aims and objectives of this present study were to determine the common ocular complications in patients suffering from diabetes.

Materials and Methods: A total of 72 patients with ocular complications of diabetes in one or both eyes attending in ophthalmology outpatient department were included in the study.

Results: Out of the 72 patients 28 patients (38.89\%) were belonged to be in the age group of 51-60 years followed by 22 patients (30.50\%) was from 61-70 years. The average age of the patients studied was 51.6yrs. $48(66.67 \%)$ patients were male while $24(33.33 \%)$ patients were female. Retinopathy was the most common ocular complication occurring in 47 (65.27\%) diabetes mellitus patients. The prevalence of cataract was in 17 patients (23.61\%) followed by Primary open angle glaucoma 01 (1.38\%) and extra ocular muscle palsy 01(1.38\%). We found significant association between sex and ocular complication of diabetes mellitus wherein cataract was more common in female diabetes patients $11(64.70 \%)$ as compared to male patients 06 (35.3\%). The prevalence of NPDR was higher in male diabetes patients $32(68.1 \%)$ than in female diabetes patients 15(31.9\%). Our study showed a higher prevalence of DR amongst male subjects. The most notable complication seen with increased duration of diabetes was non proliferative diabetic retinopathy. A non significant association was noted between ages of the diabetic patient and associated ocular complication.

Conclusion: Diabetic retinopathy was the commonest ocular complication of diabetes, followed by cataract and primary open angle glaucoma. The prevalence of diabetic retinopathy was higher in patients with longer duration of diabetes.

Keywords: Diabetes, Ocular complications, Diabetic retinopathy, cataract.
\end{abstract}

\section{Introduction}

Prevalence and incidence of diabetes mellitus increases with advancing age. The number of people over 60 years of age in India will increase from76 million in 2000 to 137 million by 2021. It is proposed that the diabetes patients in India will 
increase from 19 million to 57 million between 1995 and 2025 (195\% increase) and young diabetes individuals are increase risk of early vision threatening retinopathies.

A fourth of the world's blind population about 912 million people is estimated to be resides in India. Increase in chronic disease prevalence and their complications will add hugely to this number. As rural areas in India rapidly urbanize, persons are more prone for diabetes to reach epidemic proportions and there are increase possibility of visual impairment.

The most important complications include xanthelasmata, blepharitis, recurrent hordeolum, eczema in eyelids, microaneurysms, venous dilatation in conjunctiva in folds of Descement's membrane, neurotrophic keratitis in cornea, iris pigments on lens, rubeosis iridis in iris, rigid pupil, light near dissociation in pupils , cataract, refractive errors in lens, vitreous hemorrhage, asteroid hyalosis in vitreous, Diabetic retinopathy, retinal vein occlusion, Lipaemia retinalis.

In retina, Ischemic papillitis, Optic atrophy in Optic nerve, Palsy caused by 3rd, 4th, 6th cranial nerve involvement in Extra-ocular Muscles, Mucormycosis in orbit, Primary Open angle glaucoma, Neovascular glaucoma in Intra-ocular pressure.

\section{Materials and Methods}

Present study was conducted in the Department of Ophthalmology, Sri Krishna Medical College and Hospital, Muzaffarpur, Bihar during the period of May 2019 to October 2019. A total of 72 patients suffering from type-2 diabetes mellitus, aged between 40 to 75 years attending in ophthalmology OPD presenting with symptoms with ocular complications in one or both eyes due to diabetes mellitus were included in the Study.

All known cases of type- 1 and type -2 diabetes mellitus on regular treatment as well as those who have discontinued treatment or not on regular treatment were included in the study, Cases of Gestational diabetes mellitus and known cases of hypertension were excluded from the study.
After detailed medical and surgical history a thorough clinical examination was done. Ocular examination was done by Standard techniques and equipment. Detailed examination of the anterior segment and extra ocular movements were checked. Retinal evaluation was done using a direct or indirect ophthalmoscope or 90D lens on slit lamp biomicroscopy or by fundus photography. Grading of the retinopathy and the presence of macular edema were noted. Corneal sensations were checked using a wisp of sterile cotton. Visual acuity assessment and refraction Slit lamp examination were done. All the Data was noted using a predesigned Performa.

Routine laboratory investigations were done in every cases (blood sugar fasting and $\mathrm{pp}, \mathrm{Hba}_{1} \mathrm{c}$, routine urine, viral marker, $\mathrm{cbc}, \mathrm{lft}, \mathrm{kft}$ and tsh). The diagnosis of the ocular complication was done and treated accordingly.

\section{Results}

Out of the 72 patients 28 patients $(38.89 \%)$ were belonged to be in the age group of 51-60 years followed by 22 patients $(30.50 \%$ ) was from $61-70$ years. The average age of the patients studied was 51.6yrs. 48 (66.67\%) patients were male while 24 (33.33\%) patients were female. 64 patients were on oral anti diabetic treatment and 08 patients were on insulin.

Table-1 shows total no. of patients according to Age

\begin{tabular}{|l|c|c|}
\hline Age of patients in years & Total no. of patients & Percentage \\
\hline $40-50$ & 8 & 11.11 \\
\hline $51-60$ & 28 & 38.89 \\
\hline $61-70$ & 22 & 30.55 \\
\hline More than 70 & 14 & 19.44 \\
\hline Total (n) & 72 & \\
\hline
\end{tabular}

Table-2 shows total no. of patients with ocular complication and their frequency of occurrence

\begin{tabular}{|l|c|c|}
\hline Ocular complication & $\begin{array}{c}\text { Total no. of } \\
\text { patients }(\mathrm{n}=72)\end{array}$ & Percentage \\
\hline Primary open angle glaucoma & 1 & 1.38 \\
\hline Cataract & 17 & 23.61 \\
\hline Recurrent styes & 1 & 1.38 \\
\hline Transient change in refraction & 1 & 1.38 \\
\hline Recurrent Lacrimal abscess & 1 & 1.38 \\
\hline Extra ocular muscle palsy & 2 & 2.77 \\
\hline Retinopathy & 47 & 65.27 \\
\hline Optic Atrophy & 1 & 1.38 \\
\hline Branch retinal vein occlusion & 00 & 00 \\
\hline Orbital cellulitis & 00 & 00 \\
\hline
\end{tabular}


Retinopathy was the most common ocular complication occurring in $47(65.27 \%)$ diabetes mellitus patients. The prevalence of cataract was in 17 patients $(23.61 \%)$ followed by Primary open angle glaucoma $01(1.38 \%)$ and extra ocular muscle palsy $01(1.38 \%)$.

Table-3 shows total no. of patients with ocular complication according to sex difference

\begin{tabular}{|l|c|c|}
\hline Ocular complication & Male & Female \\
\hline Cataract $(\mathrm{n}=17)$ & $6(35.3 \%)$ & $11(64.7 \%)$ \\
\hline NPDR $(\mathrm{n}=47)$ & $32(68.1 \%)$ & $15(31.9 \%)$ \\
\hline
\end{tabular}

We found significant association between sex and ocular complication of diabetes mellitus wherein cataract was more common in female diabetes patients $11(64.70 \%)$ as compared to male patients 06 (35.3\%). The prevalence of NPDR was higher in male diabetes patients $32(68.1 \%)$ than in female diabetes patients $15(31.9 \%)$. Our study showed a higher prevalence of DR amongst male subjects.

Significant correlation was found between duration of diabetes and associated ocular complication. NPDR was seen in $45(62.5 \%)$ patients with diabetes for 6-10 year duration.

Increased incidence of CSME was found as the duration of diabetes increased $4(5.5 \%)$ of patients with diabetes in the duration of 6-10yrs while 7 $(9.7 \%)$ of patients with diabetes in the duration range of more than 10 years had CSME (Clinically significant macular oedema).

Patients with controlled diabetes or taking regular treatment had lower prevalence of NPDR when compared to the patients not taking treatment regularly. A non significant association was found in treatment of diabetes and severity of NPDR.

\section{Discussion}

In the present study, we found retinopathy was the most common ocular complication occurring in diabetes subjects $(65.27 \%)$. The prevalence of cataract was $23.61 \%$ followed by Primary open angle glaucoma $(1.38 \%)$ and extra ocular muscle palsy $(1.38 \%)$.
The prevalence of diabetic retinopathy varied from $26.4 \%$ in persons who had diabetes for less than five years to $76.2 \%$ in persons who had diabetes for 15 or more years in a study conducted by Klein et al. Findings similar our present study regarding primary open angle glaucoma prevalence was found in studies conducted by Dobson and Girard.

Diabetes is the underlying cause in $25-30 \%$ of patients aged 45 years and older who develop acute extra ocular muscle palsy. In a study by Watanabe $\mathrm{K}, 1 \%$ of patients with diabetes were found to have cranial nerve palsies, compared with only $0.13 \%$ of control subjects.

In our study most of the patients were found to be in the age group of 51-60 years were $38.89 \%$. The average age of the patients studied was $51.8 \mathrm{yrs}$. A non significant association was found between age group and ocular complication of diabetes mellitus. Comparable age distribution was found in a study Raheja.

In the present study 48 patients were male while 24 patients were female similar sex distribution where in males outnumbering females was found in a study, conducted by Muawyah.

We found significant association between sex and ocular complication of diabetes mellitus where cataract was more common in female diabetes patients $(64.70 \%)$ as compared to male patient $(35.31 \%)$. The prevalence of NPDR was higher in male diabetes patients $(68.1 \%)$ than female diabetes patients $(31.9 \%)$.A increased prevalence of cataract was reporter in female diabetes patients in a study by Raman.

Our study showed a higher prevalence of DR amongst male subjects, Wisconsin Epidemiological study of Diabetes Retinopathy found higher prevalence of Diabetic Retinopathy in females. This discrimination may be because of low female population in the studied group. A comparable result with regard to increased incidence of diabetic retinopathy in male patients was found in a study by Sunil Gupta.

Characteristic diabetic cataract was found in only $3(17.64 \%)$ of patients with cataract. The highest 
incidence of cataract was found in the 41-45 yrs age group. Cataract was more common in female patients $(64.70 \%)$. Increased incidence of cataract in female diabetic patients was also noted similarly in a study by Harding et al and Raman. In this study we found a significant correlation between duration of diabetes and associated ocular complication. The most notable complications seen with increased duration of diabetes was NPDR seen in $62.5 \%$ patients with diabetes for 610 year duration. Increased incidence of retinopathy with increase in duration of diabetes was noted in studies conducted by Klein et al and Yank et al.

Increased incidence of CSME was noted as the duration of diabetes increased $5.5 \%$ of patients with diabetes in the duration range of 6-10yrs had CSME while $9.7 \%$ of patients with diabetes in the duration range of more than 10 years had CSME. Similar increased incidence of CSME with increased duration of diabetes was noted in a study by Varna et al.

Retinopathy occurred more frequently among those in the irregular follow-up, noted that patients with good diabetic control had lesser prevalence of NPDR when compared with subjects with bad diabetic control. Diabetes control and complication trial and United Kingdom prospective diabetic study both showed that intensive blood glucose control retards the rate of progression of diabetic retinopathy.

We found a significant association between ocular complication of diabetes and presence of family history of diabetes. 06 patients had positive family history in this study. Munen also noted that familial inheritance of diabetes is a well known complication

\section{Conclusion}

Diabetic retinopathy was the commonest ocular complication of diabetes, followed by cataract, primary open angle glaucoma and extra ocular muscle palsy. The prevalence of maculopathy was greater in subjects with type -2 diabetes mellitus. Prevalence of diabetic retinopathy was higher in patients with longer duration and with poor control of diabetes.

\section{References}

1. Narendran V, John R.K, Raghuram A, Ravindran R.D, Nirmalan P.K, Thulasiraj R.D. Diabetic retinopathy among self reported diabetics in southern India: a population based assessment. $\mathrm{Br} \mathrm{J}$ of Ophthalmol 2002 Sep; 86(9): 1014-1018.

2. Cavalleranoj Ocular manifestations of diabetes mellitus. Optom Clin 1992; 2:93116.

3. Klein R, Klein BE, Moss SE, Davis MD, DeMets DL: The Wisconsin Epidemiologic Study of Diabetic Retinopathy. II. Prevalence and risk of diabetic retinopathy when age at diagnosis is less than 30 years. Arch Ophthalmol 1984; 102:527-532.

4. Armstrong JR, Daily RK, Dobson HL, Girard LW The incidence of glaucoma in diabetes mellitus. A comparision with the incidence of glaucoma in the general population. Am J Ophthalmol 1960; 50:55.

5. Rush JA. Extra ocular muscle palsies in diabetes mellitus. International Ophthalmology Clinics 1984; 24:155-159.

6. Watanabe $\mathrm{K}$, et al: Characteristics of cranial nerve palsies in diabetic patients. Diabetes Res ClinPract 10:19-27, 1990.

7. Raheja BS. Diab Care Asia-India Study: diabetes care in India-current status.J Assoc Physicians India. 2001 Jul;49:71722.

8. Al-Bdour MD, A1-Till MI, Samra KM. Risk factors for diabetic retinopathy among Jordanian diabetics. Middle East J Ophthalmol 2008:15(2);p 77-80.

9. Raman R, Pal SS, Adams JS, Rani PK, Vaitheeswaran K, Sharma T. Prevalence and Risk Factors for Cataract in Diabetes. Sankara Nethralaya Diabetic Retinopathy Epidemiology And Molecular Genetics 
Study Report No 17. Invest Ophthalmol Vis Sci 2010.

10. Klein R, Klein BE, Moss SE, Davis MD, DeMets DL: The Wisconsin Epidemiologic Study of Diabetic Retinopathy. II. Prevalence and risk of diabetic retinopathy when age at diagnosis is less than 30 years.Arch Ophthalmol 1984; 102:520-526.

11. Klein R, Klein BE, Moss SE, Davis MD, DeMets DL: The Wisconsin Epidemiologic Study of Diabetic Retinopathy. III. Prevalence and risk of diabetic retinopathy when age at diagnosis is 30 or more years. Arch Ophthalmol 102: 527- 532,1984.

12. Gupta S, Ambade A. Prevalence of diabetic retinopathy and influencing factors amongst type 2 diabetics from central India \Int J Diab Dev Ctries 2004: 24:75-8.

13. Bron AJ, Sparrow J,Brown NAP, Harding JJ.The lens in diabetes. Eye1993; 7:260275.

14. Klein R, Klein B, Moss S, et al: The Wisconsin epidemiologic study of diabetic retinopathy. XIV. Ten-year incidence and progression of diabetic retinopathy. Arch Ophthalmol 1994;112:1217-1228.

15. Yanko L, Goldbourt U, Michaelson C. et $\mathrm{al}$ : Prevalence and 15-year incidence retinopathy and associated characteristics in middle-aged and elderly diabetic runner. Br J Ophthalmol 1983;67:759-765. 